\title{
DUPLA DESTILAÇÃO DA AGUARDENTE DE CANA: TEORES DE ACIDEZ TOTAL E DE COBRE ${ }^{1}$
}

\author{
Leandro César Bizelli; Carlos Alberto França Ribeiro²; Fernando Valadares Novaes ${ }^{3 *}$

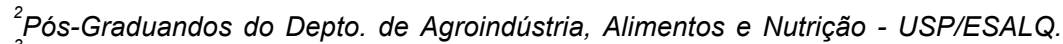 \\ ${ }^{3}$ Depto. de Agroindústria, Alimentos e Nutrição - USP/ESALQ, C.P. 9 - CEP: 13418-900 - Piracicaba, SP. \\ *Autor correspondente <fvnovaes@terra.com.br>
}

RESUMO: Este trabalho foi desenvolvido com o objetivo de avaliar a influência da condução da destilação sobre os teores de acidez e de cobre da aguardente de cana. Duas técnicas de destilação em alambiques simples foram confrontadas, a destilação convencional (Tratamento A.M.) e a dupla destilação (Tratamento A.B.). Houve influência positiva da dupla destilação sobre as características físico-químicas da aguardente, com redução nos teores de cobre e acidez acética, dentre outros parâmetros tecnológicos analisados.

Palavras-chave: aguardente de cana, acidez, cobre, destilação

\section{DOUBLE DISTILLATION OF SUGAR CANE SPIRIT: COPPER AND TOTAL ACIDITY CONTENTS}

\begin{abstract}
Two distillation techniques, conventional distillation and double distillation were compared employing pot stills. Analysis of the results indicated a positive influence of the double distillation technique on the physical and chemical characteristics of the spirit. Lower levels of copper and total acidity were obtained as compared to those of conventional distillation.

Key words: sugar cane spirit, acidity, copper, distillation
\end{abstract}

\section{INTRODUÇÃO}

A aguardente de cana surgiu nos primórdios de nossa colonização, logo que os canaviais foram plantados e os engenhos de açúcar passaram a moer cana, tendo desde então participação importante em nossa economia, quer como fonte de renda para meeiros e arrendatários ou como moeda para contrabandistas que a trocavam por escravos na costa africana no denominado comércio triangular.

Apesar do grande volume produzido e comercializado, a qualidade de grande parte das aguardentes deixa muito a desejar, devido ao fato de muitos leigos ou mesmo curiosos estarem à frente das unidades produtoras, executando o processo muitas vezes de maneira empírica e rudimentar, baseados no senso comum e informações errôneas que muitas vezes passam de pai para filho.

Ao contrário de outros povos, que criaram, aprimoraram e projetaram seus destilados, aqui a aguardente é considerada bebida de segunda categoria, porém, a melhoria da qualidade, a adequação e inovação dos processos, aos poucos têm rendido bons frutos. Conseqüentemente, surgem novos mercados e novos consumidores. Assim é que o processo de dupla destilação, usual na grande maioria dos outros destilados, vem de encontro com a busca da tão almejada qualidade, colocando em pé de igualdade a aguardente de cana com outros tantos destilados famosos.
Após a fermentação, o mosto de cana passa a ser chamado vinho, compõe-se de água e álcool etílico em maiores proporções, e muitos outros compostos que constituem a chamada "fração não álcool", ou também denominada "componentes secundários", substâncias essas responsáveis pelo sabor e aroma das aguardentes. Os principais componentes da fração não álcool são: aldeído acético, ácido acético e ésteres desses ácidos, furfural e álcoois superiores como o amílico, isoamílico, butílico, isobutílico, propílico e isopropílico (Lima, 1983).

Os vinhos contêm um grande número de compostos voláteis que destilam segundo três critérios: ponto de ebulição, afinidade com o álcool ou água e teor alcoólico no vapor durante a destilação (Léauté, 1990).

O comportamento das diferentes impurezas (compostos secundários) em relação ao álcool etílico no decorrer de qualquer operação de destilação está relacionado às suas diferentes solubilidades no etanol, segundo Ernesto Sorel citado por Novaes (1994).

Análises efetuadas por cromatografia gasosa têm demonstrado que, além da água e do álcool etílico, um destilado bruto apresenta cerca de duas centenas de outros componentes voláteis, dos quais a quase totalidade tem natureza líquida. Considerando individualmente aquelas substâncias, verifica-se que seus pontos de ebulição variam desde $19^{\circ} \mathrm{C}$ até $268^{\circ} \mathrm{C}$, sendo muito próximos uns dos outros e, algumas vezes, praticamente coincidentes. Tal fato, por si só já demonstra a dificuldade

Parte da Dissertação de Mestrado do primeiro autor apresentada à USP/ESALQ - Piracicaba, SP. 
em separá-los do álcool etílico, aliado ainda à miscibilidade que ocorre entre algumas das substâncias e em relação ao próprio álcool (Novaes, 1994).

Os componentes voláteis do vinho possuem diferentes graus de volatilidade, sendo possível a separação por processo de destilação. Assim, os componentes mais voláteis são recolhidos na primeira fração do destilado denominado de "cabeça", e os menos voláteis nas frações finais, "cauda". A porção intermediária é conhecida como "coração" e é constituída principalmente de frações medianamente voláteis (Yokoya, 1995).

Segundo Barbet, citado por Novaes (1994), no que diz respeito à volatilidade, são denominados de produtos de "cabeça" aqueles que apresentam ponto de ebulição inferior ao do álcool etílico e produtos de "cauda" os que possuem ponto de ebulição superior a ele. Contudo, determinados compostos se comportam ora como produtos de "cabeça", ora como produtos de "cauda", segundo a concentração alcoólica do líquido submetido à destilação.

Yokoya (1995) acrescenta ainda que o comportamento dos compostos secundários na destilação depende das suas propriedades termodinâmicas. Os diversos compostos secundários no vinho podem ser agrupados em três categorias: a) Compostos mais voláteis que o álcool, representados por ésteres e muitos aldeídos, são mais freqüentes na fração "cabeça"; b) compostos menos voláteis que o álcool, representados por compostos fenólicos e muitos ácidos orgânicos, são mais abundantes na fração "cauda"; c) compostos que são mais voláteis que o álcool nas soluções alcoólicas de baixa concentração e menos voláteis nas soluções alcoólicas concentradas.

Lucena (1957) recomenda para se obter aguardente de boa qualidade a adoção da seguinte prática: a fração "cabeça" é separada quando o alcoômetro marcar 80 a 85 `GL; em seguida destila o "coração" de 80 a $85^{\circ} \mathrm{GL}$ a $45^{\circ} \mathrm{GL}$, originando um produto com uma riqueza alcoólica média de 55 a $65^{\circ} \mathrm{GL}$, e finalmente a "cauda", sendo que os produtos extremos são adicionados na destilação posterior.

Parâmetros de qualidade são escassos, uma vez que a legislação vigente pouco rege sobre este atributo, impondo limites para a garantia da saúde pública, e que pouco ou nada se refere à qualidade global do produto (Ribeiro \& Horii, 1998).

Dentre estes parâmetros, de especial interesse, destaca-se o teor de cobre, o qual em muito têm limitado as exportações de aguardente pelas imposições legais dos potenciais países importadores (Oliveira, 1970; Faria \& Campos, 1989). Este metal é dissolvido na parte descendente do aparelho de destilação (Faria, 1989) pela dissolução do carbonato básico de cobre (azinhavre) que se forma em seu interior (Lucena, 1957).

Ribeiro (1997) mostra que durante o decorrer da destilação as primeiras porções do destilado possuem acidez elevada, diminuindo na parte intermediária, voltando a se elevar na parte final, dados anteriormente relatados por Lafon (1964) e Boza (1996).
Pelo exposto, verifica-se a importância da acidez, outro parâmetro com base legal, na qualidade da aguardente de cana, quer seja pelo seu papel no sabor e no aroma ou por sua relação com os teores de cobre.

Assim, o presente trabalho teve como objetivo verificar o efeito da dupla destilação sobre os teores de cobre e de acidez da aguardente de cana sob condições operacionais práticas, como é conduzido na maioria das unidades produtoras.

\section{MATERIAL E MÉTODOS}

Os ensaios foram realizados na planta piloto da destilaria "Professor Juvenal Mendes de Godoy" e nos laboratórios do Departamento de Agroindústria, Alimentos e Nutrição da Escola Superior de Agricultura "Luiz de Queiroz"/ Universidade de São Paulo.

Neste trabalho, visando ao estudo do efeito da condução da destilação sobre os teores de acidez total e cobre, foram realizados ensaios comparativos entre duas técnicas diferenciadas de condução da destilação.

Matéria-Prima - para a produção dos destilados, foram utilizados vinhos centrifugados oriundos da fermentação alcoólica do mosto de cana-de-açúcar, sendo esta cortada manualmente sem queima, e moída no mesmo dia do corte. O teor alcoólico desses vinhos situou-se no intervalo de $8,35 \%$ a $6,50 \% v^{-1}{ }^{-1}$, com teor médio de $7,30 \% v^{-1}$.

Condução da destilação - duas diferentes técnicas de condução de destilação constituíram os tratamentos destes ensaios, onde a destilação pelo processo convencional (tratamento A.M.) deu origem à aguardente monodestilada, e a técnica da dupla destilação (tratamento A.B.) deu origem à aguardente bidestilada, conforme descrito a seguir.

Processo convencional - a destilação do vinho foi conduzida em dois alambiques de cobre "tipo cebola", volumes úteis de 106 litros, constituídos de caldeira de destilação (cucúrbita) assentada sobre base de alvenaria; capitel, seguido de uma alonga que termina em serpentina submersa em tanque com água corrente (condensador/ resfriadeira). O sistema de aquecimento era indireto, através de vapor de água circulando no interior de serpentina submersa na carga de vinho ou seja, sem borbotagem de vapor no líquido gerador. $\mathrm{O}$ abastecimento dos alambiques era feito através de canalização própria, para condução do vinho da dorna volante para caixa de recalque, e desta para os alambiques, sob adequada assepsia das tubulações e dos equipamentos.

Após aquecimento, iniciada a corrida do destilado, o mesmo era recebido em recipiente à saída do registro, até que o seu teor alcoólico médio no interior deste recipiente coletor acusasse $45 \pm 1 \%$ a $20^{\circ} \mathrm{C}$, quando então era considerada encerrada a operação. Este produto obtido por destilação simples foi posteriormente padronizado, originando a "aguardente monodestilada" (Tratamento A.M.). 
Processo da dupla destilação - no processo da dupladestilação (Tratamento A.B.), o vinho era destilado em uma primeira etapa dando origem ao "flegma"; este, por sua vez, sofria uma nova destilação dando origem à "aguardente bidestilada", seguindo metodologia descrita a seguir:

Obtenção do flegma - a destilação do vinho para obtenção do flegma também foi conduzida nos alambiques descritos anteriormente.

Após aquecimento, iniciada a corrida do destilado, este era coletado em recipiente adequado, até que o seu teor alcoólico à saída do registro do condensador acusasse cerca de $5 \%$ de álcool em volume. Este processo de obtenção do flegma, era realizado por três vezes, para se obter volume suficiente para preencher a carga útil do aparelho de destilação. Deste modo, ao final destas três destilações, os destilados obtidos eram misturados entre si, conseguindo-se então os volumes necessários à redestilação.

Obtenção do destilado final - o destilado final referente ao Tratamento A.B. foi obtido pela redestilação do flegma.

Para obtenção da "aguardente bidestilada", a mistura dos "flegmas" passou por uma segunda destilação, na qual houve fracionamento no recolhimento deste segundo destilado em frações denominadas "cabeças", "coração" e "cauda".

A fração "cabeças" correspondeu à parte inicial da corrida, cujo teor alcoólico médio esteve em torno de $70 \%$ $\mathrm{v} \mathrm{v}^{-1}$ a $20^{\circ} \mathrm{C}$, semelhante à técnica de Léauté (1990).

Da mesma forma a fração "coração", principal objetivo dessa segunda destilação, e que posteriormente seria utilizada na elaboração da futura bebida, correspondeu à parte intermediária da corrida, cujo teor alcoólico esteve em torno de $65 \pm 1 \%$ a $20^{\circ} \mathrm{C}$.

A fração "cauda" correspondeu à parte final da corrida, isto é, do final da fração "coração" até que o teor alcoólico na corrida acusasse cerca de $5 \%$ a $20^{\circ} \mathrm{C}$, pois com esta concentração de álcool na corrida, o teor alcoólico do flegma contido na caldeira já estaria praticamente esgotado, como recomendado por Valsechi (1970).

As frações "cabeças" e "cauda" eram misturadas, constituindo-se em um líquido com teor alcoólico que variou de 20 a $30 \%$ em volume. Cada terça parte desta mistura era adicionada a uma nova carga de vinho que, após destilação, originava o flegma. Assim, todo o volume da referida mistura era reciclado no processo, enriquecendo em álcool o vinho, permitindo, deste modo, recuperar boa parte do álcool ali contido.

Padronização dos destilados - estabeleceu-se que os produtos finais obtidos em ambos os processos deveriam apresentar um teor alcoólico da ordem de $40 \pm 1 \%$ em volume, a $20^{\circ} \mathrm{C}$.

Desse modo, através de Balanço de Massas, procedeu-se àquele ajuste, adicionando-se aos destilados água destilada para padronização de seus teores alcoólicos.
Após padronização, as amostras finais eram novamente acondicionadas em recipientes de vidro, tipo garrafão (4,6 litros) e fechados com rolhas plásticas e armazenados à temperatura ambiente, assim permanecendo até o momento das análises a que seriam submetidas.

Análises físico-químicas - as amostras coletadas diretamente de seus respectivos recipientes de armazenamento foram submetidas às seguintes determinações analíticas:

Acidez total: segundo Instituto Adolfo Lutz (1985).

Cobre: determinado pelo método químico colorimétrico, descrito por Jacinto (1967).

Análise estatística - o ensaio foi conduzido sob 0 Delineamento de Blocos Casualizados, constituindo dois tratamentos (destilação convencional e dupla destilação) e nove blocos. Cada bloco compreendia os dois tratamentos de destilação de vinho oriundo da mesma batelada de fermentação, sistemática essa repetida no decorrer de todo processo de obtenção das amostras.

As médias obtidas dos tratamentos foram submetidas à Análise da Variância, segundo Gomes (1990).

\section{RESULTADOS E DISCUSSÃO}

Análise comparativa entre as aguardentes - as aguardentes já padronizadas provenientes dos tratamentos A.M. e A.B. foram submetidas às analises físico-químicas (TABELA 1).

Acidez total - a dupla destilação influiu nos teores de acidez total da aguardente, efeito visualizado pela TABELA 1 , obtendo-se com este tratamento os menores valores de acidez total $\left(17,95 \mathrm{mgCH}_{3} \mathrm{COOH} 100 \mathrm{~mL}^{-1} \mathrm{EtOH} 100 \%\right)$ comparados aos do tratamento A.M. $\left(43,95 \mathrm{mgCH}_{3} \mathrm{COOH}\right.$ $\left.100 \mathrm{~mL}^{-1} \mathrm{EtOH} 100 \%\right)(p \leq 0,01)$.

A acidez é representada por compostos solúveis principalmente em água e com elevado ponto de ebulição, que destilam nas primeiras porções do destilado, na metade final do coração e na totalidade da cauda (Léauté, 1990)

Quando se destilou o flegma, cujo teor alcoólico médio era de $25 \%$ v v ${ }^{-1}$ a $20^{\circ} \mathrm{C}$, ao final da fração "coração" o teor alcoólico daquele líquido gerador ainda era significativo, desta forma, os componentes que conferem acidez ao destilado, situaram-se em maior proporção na fração "cauda", conferindo assim à aguardente bidestilada baixos teores de acidez, fato que não ocorreu com a aguardente monodestilada submetida a uma única destilação e originada de líquido gerador de baixo teor alcoólico $(7,30 \%$ $v v^{-1}$ ) Como esses ácidos apresentam baixa volatilidade em líquido gerador de elevado teor alcoólico, como aquele do qual resultou a fração "coração", somente quando ele se encontrar mais esgotado em álcool é que tais ácidos irão se volatilizar em maior quantidade, em cuja etapa da destilação resultará a última fração, ou seja, a "cauda". 
TABELA 1 - Composição média dos destilados obtidos em ambos tratamentos.

\begin{tabular}{|c|c|c|c|}
\hline & \multicolumn{2}{|c|}{ Tratamentos } \\
\hline & & AM & $A B$ \\
\hline \multicolumn{2}{|l|}{ Componentes } & Médias & Médias \\
\hline \multicolumn{2}{|c|}{ Densidade real $\left(20 / 4^{\circ} \mathrm{C}\right)$} & 0,9469 & 0,9470 \\
\hline \multicolumn{2}{|c|}{ Grau alcóolico real \% ( $\left.\mathrm{v} \mathrm{v}^{-1}\right)$} & 40,71 & 40,66 \\
\hline \multicolumn{2}{|c|}{$\begin{array}{l}\text { Acidez Total }\left(\mathrm{mgCH}_{3} \mathrm{COOH}\right. \\
\left.100 \mathrm{~mL}^{-1} \mathrm{EtOH} 100 \%\right)\end{array}$} & 43,95 & $17,95^{1}$ \\
\hline \multicolumn{2}{|c|}{$\begin{array}{l}\text { Acidez volátil }\left(\mathrm{mgCH}_{3} \mathrm{COOH}\right. \\
\left.100 \mathrm{~mL}^{-1} \mathrm{EtOH} 100 \%\right)\end{array}$} & 42,60 & 17,00 \\
\hline \multicolumn{2}{|c|}{$\begin{array}{l}\text { Acidez fixa }\left(\mathrm{mgCH}_{3} \mathrm{COOH}\right. \\
\left.100 \mathrm{~mL}^{-1} \mathrm{EtOH} 100 \%\right)\end{array}$} & 1,35 & 0,92 \\
\hline \multicolumn{2}{|c|}{ Furfurol (mg 100mL-1 EtOH 100\%) } & 0,00 & 0,00 \\
\hline \multicolumn{2}{|l|}{ Cobre $\left(\mathrm{mg} \mathrm{L}^{-1}\right)$} & 2,67 & $0,32^{1}$ \\
\hline \multicolumn{2}{|l|}{ Extrato seco $\left(\mathrm{g} \mathrm{L}^{-1}\right)$} & 0,03 & 0,03 \\
\hline \multicolumn{2}{|c|}{$\begin{array}{l}\text { Aldeídos (mg aldeído acético } \\
100 \mathrm{~mL}^{-1} \mathrm{EtOH} 100 \% \text { ) }\end{array}$} & 21,11 & 15,80 \\
\hline \multicolumn{2}{|c|}{ Acetona (mg $100 \mathrm{~mL}^{-1} \mathrm{EtOH} 100 \%$ ) } & 1,81 & 1,68 \\
\hline Ésteres & $"$ & 20,26 & 9,74 \\
\hline Metanol & $"$ & 17,36 & 14,13 \\
\hline n-Propanol & $"$ & 27,82 & 25,20 \\
\hline i-Butano & $"$ & 81,17 & 69,34 \\
\hline n-Butanol & $"$ & 0,51 & 0,26 \\
\hline i-Amílico & $"$ & 287,91 & 254,28 \\
\hline n-Amílico & $"$ & 0,00 & 0,00 \\
\hline Álcoois superiores & $"$ & 397,17 & 349,33 \\
\hline Compostos secundá & rios " & 481,15 & 391,72 \\
\hline
\end{tabular}

${ }^{1}$ Diferença significativa $(p \leq 0,01)$

Cobre - houve diferença $(p \leq 0,01)$ entre os teores de cobre dos tratamentos, observando-se os menores valores para o tratamento A.B., conforme demonstrado pela TABELA 1.

De acordo com Lucena (1959), o cobre presente nas aguardentes é proveniente da dissolução do "azinhavre" (carbonato básico de cobre solúvel em ácido) que se forma no interior do alambique e, principalmente nas partes internas da serpentina da resfriadeira.

Desta forma, quando da destilação do flegma, conforme visto anteriormente, os vapores hidroalcoólicos ácidos destilam principalmente na fração "cauda", e como foi a fração "coração" que deu origem à aguardente bidestilada, esta apresentou teores de cobre sempre inferiores à unidade e, em alguns casos, nulos. Já a aguardente monodestilada apresentou valores superiores, porém dentro dos limites fixados pela legislação.

Nas condições em que foi realizado o experimento não foi possível estabelecer correlação entre teor de cobre e acidez, conforme ilustrado nas Figuras 1 e 2. Isto pode ter sido devido a fatores não controlados tais como, quantidade de azinhavre presente no destilador, assepsia do aparelho, tempo de formação do azinhavre, intervalo

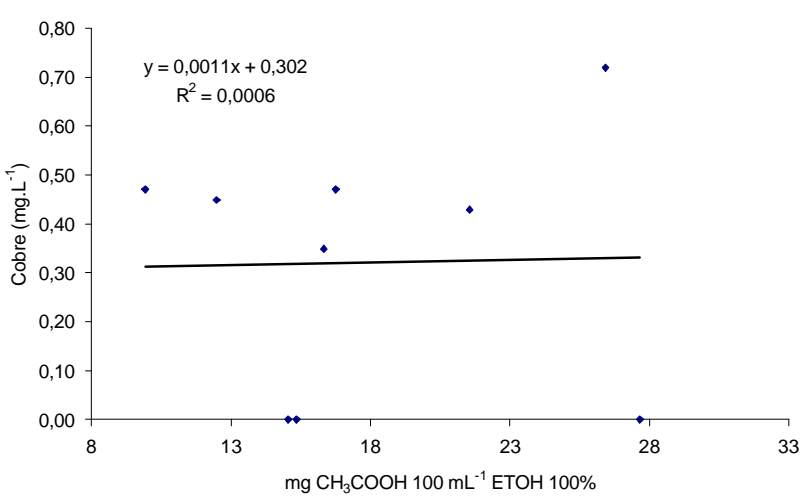

Figura 1 - Concentração de cobre em função da acidez total, no tratamento A.B.

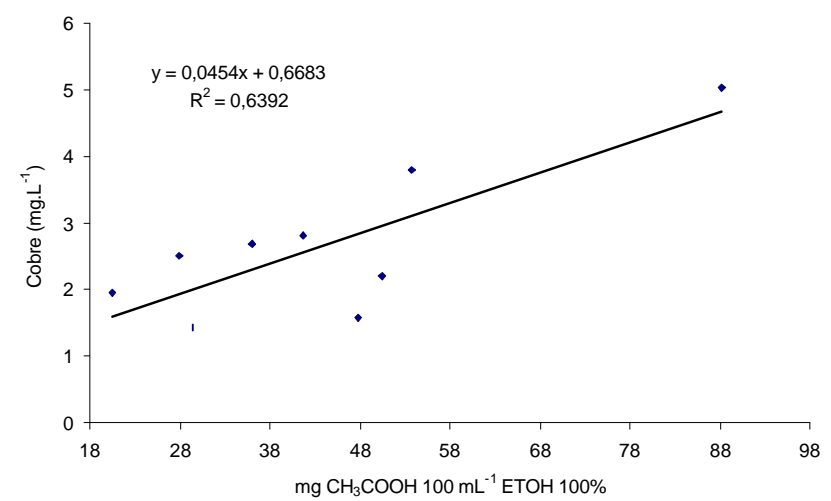

Figura 2 - Concentração cobre em função da acidez total, no tratamento A.M.

entre as diversas destilações, velocidade de destilação, temperatura de destilação, dentre outros; mostrando não ser apenas a acidez do destilado responsável pelo conteúdo de cobre, isto mostra a necessidade de estudos específicos que estabeleçam tal correlação.

\section{CONCLUSÕES}

- O produto obtido por dupla destilação se enquadra nos padrões legais vigentes no País, caracterizando-o como aguardente de cana.

- A dupla destilação permitiu a redução dos teores de cobre e da acidez total no produto bidestilado.

- A acidez total não foi o único fator responsável pelos teores de cobre nas aguardentes, sugerindo a ampliação de estudos em trabalhos futuros.

\section{REFERÊNCIAS BIBLIOGRÁFICAS}

BOZA, Y.E.A.G. Influência da condução da destilação sobre a composição e a qualidade sensorial da aguardente de cana. Piracicaba, 1996. 140p. Dissertação (Mestrado) - Escola Superior de Agricultura "Luiz de Queiroz", Universidade de São Paulo.

FARIA, J.B. A influência do cobre na qualidade da aguardente de cana ( Saccharum officinarum, L.) São Paulo, 1989. 88p. Tese (Doutorado) - Faculdade de Ciências Farmacêuticas. Universidade de São Paulo. 
FARIA, J.B.; CAMPOS, M.A.P. Eliminação do cobre contaminante das aguardentes de cana-de-açúcar brasileiras. Alimentação e Nutrição, v.1, p.117-28, 1989.

GOMES, F.P. Curso de estatística experimental. Piracicaba: Nobel,1990. cap.3, p.18-41.

INSTITUTO ADOLFO LUTZ. Normas Analíticas do Instituto Adolfo Lutz: métodos químicos e físicos para a análise de alimentos. 3. ed. São Paulo: 1985. v.1 533p.

JACINTO, A. O. Método colorimétrico do dicromato de sódio. Piracicaba, 1967. Tese (Doutorado) - Escola Superior de Agricultura "Luiz de Queiroz", Universidade de São Paulo. $82 p$.

LAFON, R. Le cognac. Paris: J. B. Bailliere e Fils, 1964.

LÉAUTÉ, R. Distillation in alambic. American Journal of Enology and Viticulture, v.41, p.90-103, 1990.

LIMA, U.A. Aguardentes. In: AQUARONE, E.; LIMA, U. de A.; BORZANI, W. Alimentos e bebidas produzidos por fermentações. São Paulo: Edgar Blucher, 1983. p.79-103. (Série Biotecnologia, 5)

LUCENA, V.G. O problema do cobre nas aguardentes. Brasil Açucareiro, v.51, p.14-18, 1959.

LUCENA, V.G. de. Componentes secundários das aguardentes. Brasil Açucareiro, v.49, p.2-4, 1957.

NOVAES, F.V. Noções básicas sobre a teoria da destilação. Piracicaba: ESALQ, Depto. de Ciência e Tecnologia Agroindustrial, 1994. 22p.
OLIVEIRA, A.J. Contribuição ao estudo da remoção do cobre da aguardente de cana-de-açúcar com resinas catiônicas. Piracicaba, 1970. 28p. Tese (Doutorado) - Escola Superior de Agricultura "Luiz de Queiroz", Universidade de São Paulo.

RIBEIRO, C.A.F. ; HORII, J. Efeito de linhagens de levedura Saccharomyces cerevisiae na tecnologia de aguardente de cana. (Compact disc). In: CONGRESSO BRASILEIRO DE CIÊNCIA E TECNOLOGIA DE ALIMENTOS, 16., Rio de Janeiro, 1998. Rio de Janeiro: SBCTA, 1998.

RIBEIRO, C.A.F. Potencialidades de diferentes linhagens de levedura da espécie Saccharomyces cerevisiae na tecnologia de aguardente de cana. Piracicaba, 1997. 107p. Dissertação (Mestrado) - Escola Superior de Agricultura "Luiz de Queiroz", Universidade de São Paulo.

SUOMALAINEN, H.; NYKANEN, L. The aroma componentes produced by yeast in nitrogen-free sugar solution. Journal of the Institute of Brewing, v.72, p.469-474, 1966.

VALSECHI, O. Aguardente de cana de açúcar. Piracicaba: Agronômica Ceres, 1970. 120p.

YOKOYA, F. Fabricação da aguardente de cana. Campinas: Fundação Tropical de Pesquisas e Tecnologia "André Tosello", 1995. 283p.

Recebido em 29.02.00 